\title{
Magnetic properties of pyroclastic rocks from the later stage of the eruptive activity of Haruna Volcano in relation to the self-reversal of thermo-remanent magnetization
}

\author{
Mituko Ozima ${ }^{1}$, Osamu Oshima ${ }^{2}$, and Minoru Funaki ${ }^{3}$ \\ ${ }^{1}$ Senkawa 1-21-11, Toshima-ku, Tokyo 171-0041, Japan \\ ${ }^{2}$ Department of Earth Science and Astronomy, Graduate School of Arts and Sciences, \\ University of Tokyo, Komaba 3-8-1, Meguro-ku, Tokyo 153-8902, Japan \\ ${ }^{3}$ National Institute of Polar Research, Kaga, Itabashi-ku, Tokyo 173-8515, Japan \\ (Received November 12, 2002; Revised February 18, 2003; Accepted March 18, 2003)
}

\begin{abstract}
Focusing to the self-reversal of Thermo-Remanent Magnetization (TRM), we examined magnetic properties of 32 pieces of unoriented pumice samples, which were systematically collected from eight layers of pumice-fall and pumice-flow deposits at Haruna Volcano, Japan in the two stages of the eruption, i.e., Futatsu-dake stage (the 5th stage) and caldera-forming stage (the 4th stage). The magnetic behaviors of TRM well correlated with the primary chemical composition $\left(\mathrm{TiO}_{2}\right.$-content or $x$ (molecular fraction value of ilmenite in $\left.x \mathrm{FeTiO}_{3}-(1-x) \mathrm{Fe}_{2} \mathrm{O}_{3}\right)$ ) of the hemoilmenite phenocrysts in the samples. That is, the samples of which chemical composition of hemoilmenite is $\mathrm{TiO}_{2} \sim 30 \mathrm{wt} \%(x \sim 0.582)$ showed various types of TRM including typical intense Self-Reversed ThermoRemanent Magnetization (SRTRM), whereas the samples of which chemical composition of hemoilmenite is $\mathrm{TiO}_{2}$ $\sim 32 \mathrm{wt} \%(x \sim 0.620)$ showed one type of TRM; weak intensity of self-reversed component of TRM. This result harmonizes with the well-known diagram by Uyeda, where the intensity of SRTRM of hemoilmenite (quenched) is an explicit function of the chemical composition, and only in the restricted narrow range of the chemical composition, intense SRTRM is acquired. Moreover, the hemoilmenite samples of which chemical composition is less than $\mathrm{TiO}_{2} \sim 31 \mathrm{wt} \%(x \sim 0.60)$ are capable to acquire various intensities of SRTRM on annealing according to its condition. In our $\mathrm{TiO}_{2}$-poorer (or smaller- $x$ ) samples, the variety in the behavior of TRM is well explained with this annealing effect in this compositional range.
\end{abstract}

Key words: Self-reversal, TRM, Haruna Volcano, dacite pumice.

\section{Introduction and Geologic Setting}

Haruna Volcano is noted for the first documentation of Self-Reversed Thermo-Remanent Magnetization (SRTRM) in hemoilmenite phenocrysts. They occur in the pumice layer of Futatsu-dake (Nagata et al., 1951), which was formed during the latest eruption of Haruna in the 6th century. The volcano, located in central Japan about $120 \mathrm{~km}$ $\mathrm{NW}$ of Tokyo (N 36 21', E 138 $52^{\prime}$ ), is a large stratovolcano about $22 \mathrm{~km}$ across with a small summit caldera $(3 \times 4$ $\mathrm{km}$ across) and more than 5 lava domes in the caldera and on the eastern middle flank. The stratovolcano, mostly made up of basic andesites, has had a complicated growth history including repetition of formation and destruction of the volcanic edifice. In contrast, the lava domes, which formed in the last post-caldera stage (ca. $40 \mathrm{ka}$ ), are wholly of dacite composition.

The latest "eruption of Futatsu-dake" displayed a complete one-cycle eruption of a dacite magma, generating a Plinian pumice fall, and then a pyroclastic pumice flow, succeeded by emergence of the residual degassed magma to the surface to form a lava dome, called the "Futatsu-dake" (Oshima, 1971, 1975). The essential material, i.e. the Futatsu-

Copy right(C) The Society of Geomagnetism and Earth, Planetary and Space Sciences (SGEPSS); The Seismological Society of Japan; The Volcanological Society of Japan; The Geodetic Society of Japan; The Japanese Society for Planetary Sciences. dake pumice (hyperthene-hornblende dacite), contains euhedral, discrete phenocrysts of iron-titanium oxides, including titanomagnetite $\left(\mathrm{TiO}_{2} \sim 6 \mathrm{wt} \%\right.$; Usp19Mt81) and hemoilmenite $\left(\mathrm{TiO}_{2} \sim 30 \mathrm{wt} \% ; x \sim 0.582\right)$ up to about $1 \mathrm{~mm}$ in diameter in transparent dacite glass about $71 \mathrm{wt} \% \mathrm{SiO}_{2}(\mathrm{Os}-$ hima, 1975). The dome lava also carries euhedral and discrete phenocrysts of both phases; however, hemoilmenite has decomposed into exsolution lamellae (Oshima, 1975, 1982) and does not show the SRTRM.

Haruna Volcano generated pyroclastic flows (Futatsu-dake and Numaogawa) not only in the latest (5th) stage (6th century) but more intensely in the caldera-forming 4th stage about 40,000 years ago. At least 6 sheets (Shirakawa, Murota, etc.) are distinguishable in the 4th stage (Oshima, 1972b), and all have euhedral and discrete phenocrysts of titanomagnetite and hemoilmenite as Fe-Ti oxide minerals (dacite pumice). As shown in Table 1, chemical compositions (obtained with X-ray microprobe) of the hemoilmenite phenocrysts are nearly the same as that of Futatsu-dake pumice (Oshima, 1972a, 1978). Moreover, hemoilmenite phenocrysts with nearly the same compositions are present in other volcanoes in Japan. This suggests that occurrence of hemoilmenite with such compositions (and SRTRM) are rather common (because of appropriate $\mathrm{T}-f_{\mathrm{O}_{2}}$ conditions) in dacite eruptions in Japan arc volcanism (Oshima, 1978). 
Table 1. List of samples.

\begin{tabular}{|c|c|c|c|c|c|c|}
\hline \multicolumn{2}{|l|}{ Sample } & \multicolumn{2}{|c|}{$\begin{array}{l}\text { Number of } \\
\text { sampling- } \\
\text { site } \quad \text { sample }\end{array}$} & Sample number & \multirow[t]{2}{*}{$\begin{array}{c}\text { Age } \\
\text { (year B.P.) }\end{array}$} & \multirow[t]{2}{*}{$\begin{array}{c}\mathrm{TiO}_{2} \text {-content in } \\
\text { hemoilmenite } \\
\text { (wt } \%)\end{array}$} \\
\hline Futatsu-dake stag & & & & & & \\
\hline \multirow[t]{2}{*}{ Futatsu-dake } & p.flow & 6 & 8 & $17,24 \mathrm{~A}, 24 \mathrm{~B}, 25,26 \mathrm{~A}, 26 \mathrm{~B}, 27,29$ & \multirow{3}{*}{$\sim 1500$} & $29.92 \pm 0.73$ \\
\hline & p.fall & 4 & 8 & $1 \mathrm{~A}, 1 \mathrm{~B}, 21 \mathrm{~A}, 21 \mathrm{~B}, 22 \mathrm{~A}, 22 \mathrm{~B}, 23 \mathrm{~A}, 23 \mathrm{~B}$ & & $\prime \prime$ \\
\hline Numaogawa & p.flow & 2 & 2 & 2,18 & & $30.28 \pm 0.40$ \\
\hline \multicolumn{7}{|c|}{ Caldera(-forming) stage } \\
\hline Shirakawa & p.flow & 3 & 3 & $3,12,31 \mathrm{~A}$ & \multirow{7}{*}{$\sim 40000$} & $32.40 \pm 0.94$ \\
\hline Murota & p.flow & 4 & 4 & $6,7,8,9$ & & $32.22 \pm 1.42$ \\
\hline Hassaki & p.fall & 2 & 2 & 10,11 & & $\prime \prime$ \\
\hline Tenaga & p.flow & 1 & 1 & 14 & & $31.57 \pm 1.80$ \\
\hline \multirow[t]{2}{*}{ Miyazawa } & p.flow & 2 & 2 & 4,13 & & $31.52 \pm 0.45$ \\
\hline & p.fall & 1 & 1 & 19 & & 11 \\
\hline Dai-ichi & p.flow & 1 & 1 & 5 & & $30.36 \pm 0.57$ \\
\hline
\end{tabular}

SRTRM in hemoilmenite in dacite pumice has also been reported from other localities in the world. Noted examples are in the Brunhes eruption in Natib (Kennedy, 1981), in the pumice of the 1985 eruption of Nevado del Ruiz (Heller et al., 1986), in the 10-ka eruption of Mount Shasta (Lawson et al., 1987), and in the 1991 eruption of Pinatubo (Ozima et al., 1992).

The model of the mechanism of SRTRM in hemoilmenite, established by Ishikawa and Syono (1962, 1963), has subsequently been questioned and some alternate models proposed (Lawson et al., 1987; Hoffman, 1992; Hoffmann and Fehr, 1996; Prévot et al., 2001). Some of the alternative models are based on micromagnetic observational results (Bitter patterns) on hemoilmenite crystals of Pinatubo samples. From the viewpoint that the mechanism of SRTRM of hemoilmenite should be common in Pinatubo as well as in Haruna samples, two of the present authors examined micromagnetic properties of hemoilmenite crystals of some "Haruna samples": the results differed from those reported on Pinatubo samples (Ozima and Funaki, 2001). Both the Haruna and Pinatubo samples are dacite pumices and show the same magnetic phenomenon (SRTRM of hemoilmenite crystals); yet, the micromagnetic properties observed with Bitter-technique in these two (Pinatubo and Haruna) samples substantially differ. Possibly, "the true mechanism" of SRTRM in hemoilmenite crystals is not reflected in the wall structures visualized by the Bitter-technique but is masked by other factors. Or, possibly, the Pinatubo or Haruna hemoilmenite crystals observed micromagnetically were not the real carrier of SRTRM.

To clarify the mechanism of SRTRM of hemoilmenite, combining the geological evidences of samples from Haruna Volcano and their magnetic properties, and hoping to establish a comprehensive SRTRM mechanism, we collected unoriented pumice samples from Haruna Volcano and examined their magnetic properties (NRM and TRM). In this paper, we report the experimental results on the magnetic properties of these pumice samples.

\section{Samples}

In total, 32 unoriented pumice samples from Haruna Volcano were used for the experiments (Table 1). Of them,
18 are from Futatsu-dake and Numaogawa (pumice fall and pumice flow) and $1 \sim 4$ are from several other deposits. In Table 1, the numbers of the sampling-site and sample, and sample-number are listed. All samples are pyroclastic rocks, such as pumice fall or pumice flow, containing discrete euhedral phenocrysts of both $\alpha$ - and $\beta$-phases. As shown in Table 1 , these samples are divided into two stages at a geological boundary (5th and 4th stages) between Numaogawa and Shirakawa. Therefore, we treat Futatsu-dake and Numaogawa samples together as "Futatsu-dake stage" (5th stage) samples and the other as "caldera (-forming) stage" (4th stage) samples. Generally, the chemical compositions of $\alpha$-phase crystals contain $\sim 30 \mathrm{wt} \%$ in $\mathrm{TiO}_{2}$-content $(x \sim 0.60 \sim$ 0.55 : hemoilmenite). The compositions within a grain are almost homogeneous in each crystal grain and constant between grains in samples from the same sheet. The value of the $\mathrm{TiO}_{2}$-content (Table 1) includes the range of measurement error. It is clear that there is a distinct difference in the chemical composition between the two stages. The chemical composition of hemoilmenite of the caldera stage samples (except the Dai-ichi pumice flow) is richer in $\mathrm{TiO}_{2}$-content than that of Futatsu-dake stage samples by $\sim 2 \mathrm{wt} \%$, a difference related to primary condition at liquidus crystallization.

Each rock-sample was cut into a cylindrical shape of 2.4 $\mathrm{cm}$ in diameter and in height. Subsequently, we measured their remanent magnetization.

\section{Experimental Results}

Initially, all samples were subjected to NRM measurement, followed by AF-demagnetization. After that, TRM of all samples was acquired by cooling from $600^{\circ} \mathrm{C}$ in $50 \mu \mathrm{T}$; subsequently this TRM was thermally demagnetized. Figure 1 and 2 show the progressive AF-demagnetization of the total intensity of NRM of some selected Futatsu-dake stage samples and caldera stage samples, respectively. There are two typical types of AF decay: monotonic decay and convex decay. Figure 3 and 4 show the thermal-demagnetization curves of TRM along the applied field of all the Futatsu-dake stage samples and of all the caldera stage samples, respectively. There are two types of apparent TRM at room temperature, called here type-A and type-B. Type-A is reversed whereas type- $\mathrm{B}$ is normal. These thermal-demagnetization 


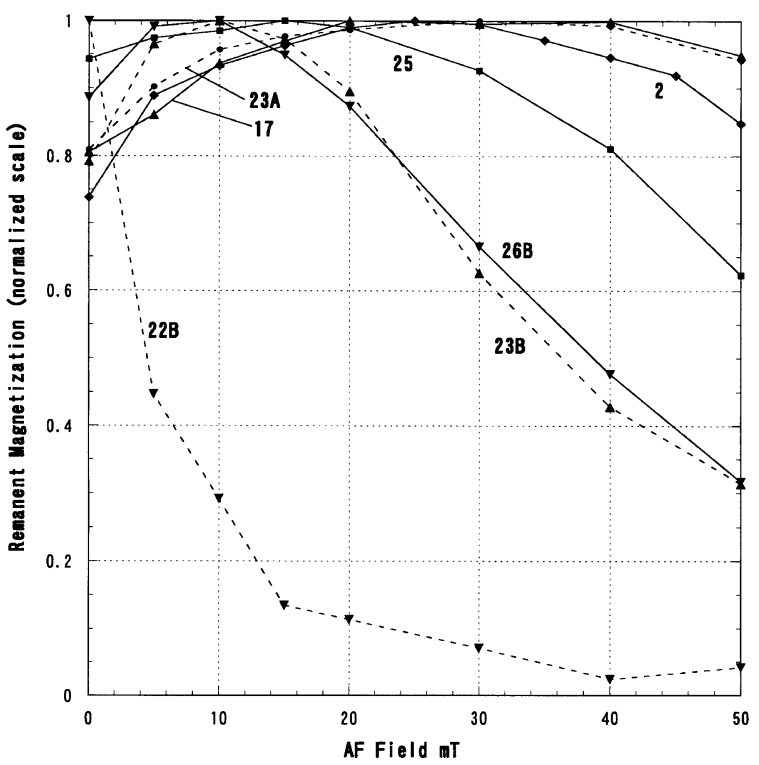

Fig. 1. AF-demagnetization of NRM of the selected Futatsu-dake stage samples. The ordinate shows the total intensity of NRM in normalized scale. Numbers indicate samples shown in Table 1. Pumice flow samples are shown by solid lines and pumice fall samples by broken lines.

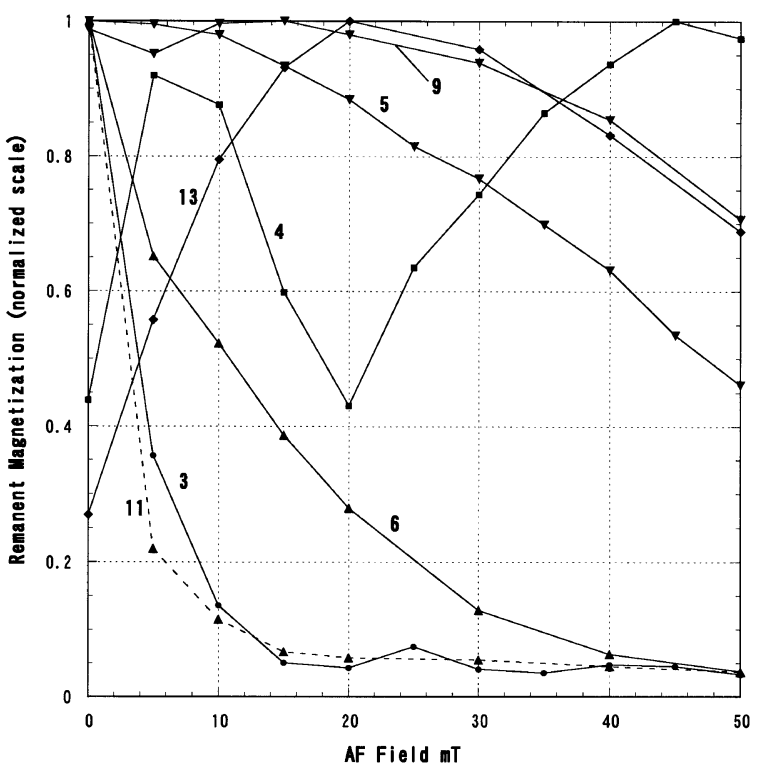

Fig. 2. AF-demagnetization of NRM of the selected caldera stage samples. The ordinate shows the total intensity of NRM in normalized scale. Numbers indicate samples shown in Table 1. Pumice flow samples are shown by solid lines and pumice fall samples by broken lines.

curves are well correlated with AF-demagnetization curves similarly as in the case of Futatsu-dake pumice samples in Ozima and Funaki (2001).

On thermal-demagnetization, reversed TRM (type-A) shows the typical thermal demagnetization decay of SRTRM described by Ozima and Funaki (2001) (e.g., sample H1). It is clear that the normal component of TRM carried by the $\beta$-phase exists but this is weaker than the reversed component of TRM carried by hemoilmenite. On thermaldemagnetization of some of the normal TRM (type-B) samples, the intensity initially decreases $\sim 200-300^{\circ} \mathrm{C}$, recovers at higher temperature reaching a maximal value, and then

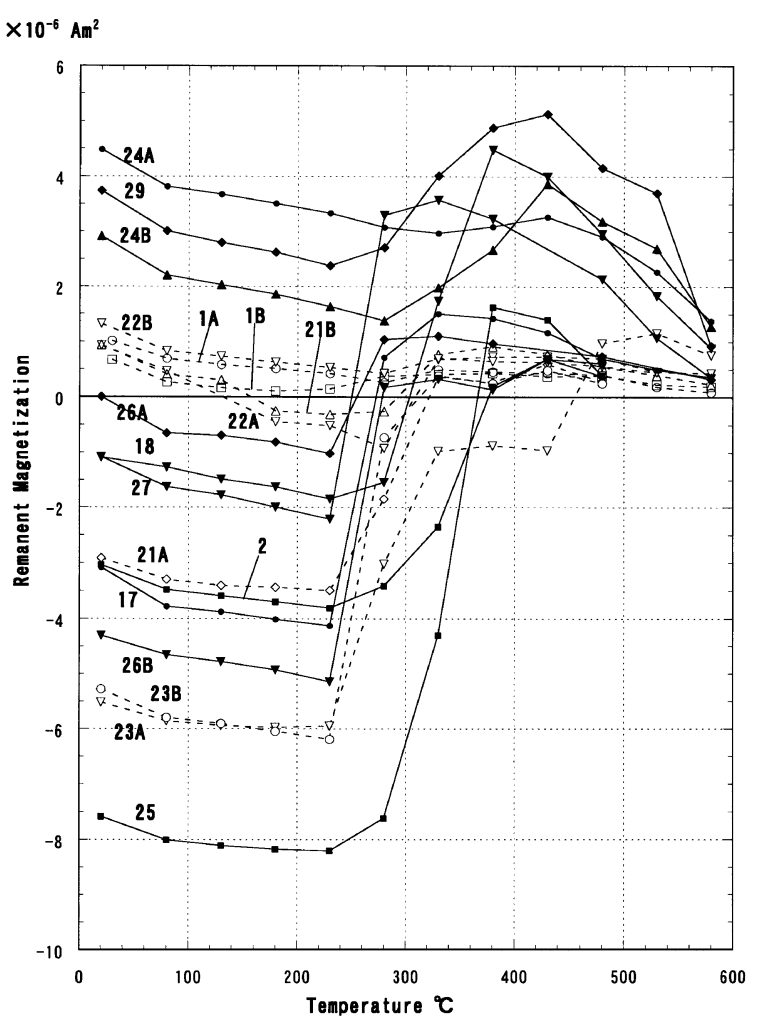

Fig. 3. Thermal-demagnetization of TRM of the Futatsu-dake stage samples. The ordinate shows TRM of $2.4 \mathrm{~cm}$-core along the applied field Numbers indicate samples shown in Table 1. Pumice flow samples are shown by solid lines and pumice fall samples by broken lines.

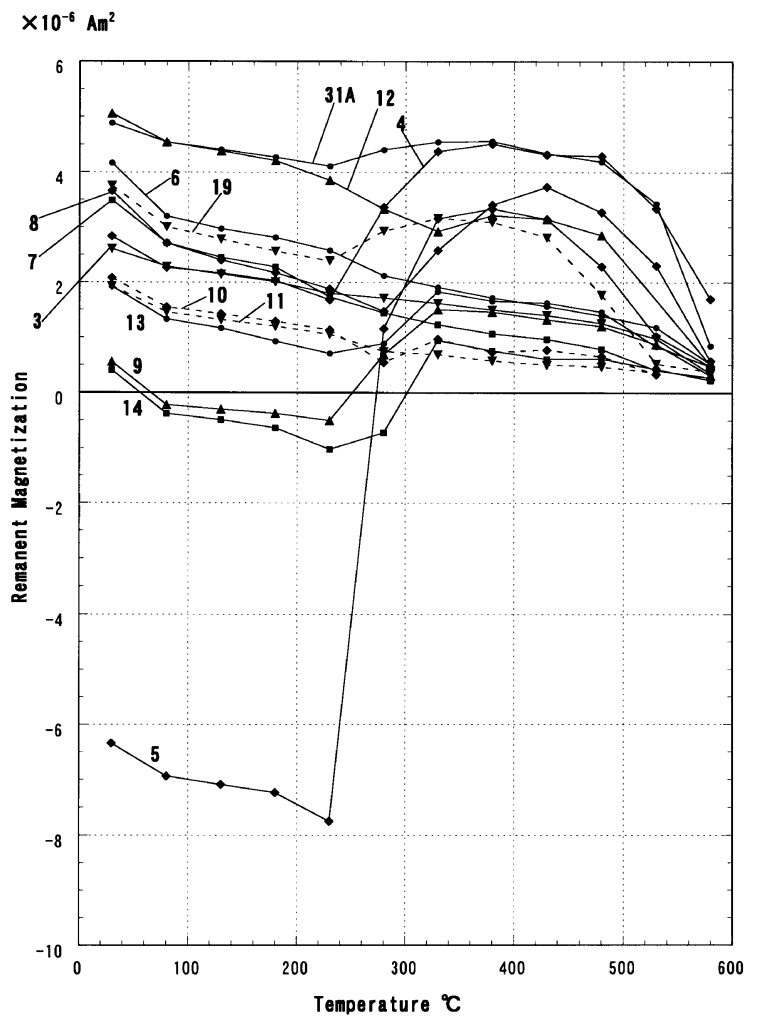

Fig. 4. Thermal-demagnetization of TRM of caldera stage samples. The ordinate shows TRM of $2.4 \mathrm{~cm}$-core along the applied field. Numbers indicate samples shown in Table 1. Pumice flow samples are shown by solid lines and pumice fall samples by broken lines. 
vanishes finally $\sim 500-600^{\circ} \mathrm{C}$. This shape is typical thermal demagnetization curve of normal TRM of "Haruna samples" (e.g., sample H1' in Ozima and Funaki (2001)). Because the shape resembles that of a lower-case, $n$, we have termed this type of thermal decay the "n-type". In a few cases of the normal TRM (type-B), the intensity of TRM decreases almost monotonically and vanishes $\sim 500-600^{\circ} \mathrm{C}$. In the former case (type-B1, or n-type), it is likely that the normal component of TRM carried by the $\beta$-phase is sufficiently strong that it overcomes the self-reversed component of TRM carried by hemoilmenite. In the latter case (type-B2), it seems that hemoilmenite has little role on the reversed TRM, or hemoilmenite itself is scarcely contained in these samples. The type-A demagnetization-curve is regarded as a deformed n-type and types A and B1 are essentially the same in quality in the sense that hemoilmenite in these pumice samples possesses self-reversed component more or less. In other words, the relative intensity of the reversed component of TRM against that of the normal component of TRM differentiates the type of the thermal demagnetization curve (type-A or type-B1 (n-type)).

\section{Discussion}

In 1953, Nagata et al. reported that, "Besides the dacitic pumice of Mt. Haruna, an igneous rock having the tendency of self-reversal of thermo-remanent magnetization has been found in a pitchstone of Mt. Asio. Although the self-reversal property of the Asio ferromagnetic minerals is weaker than that of the Haruna ferromagnetic minerals, the magnetic and crystallographic properties of the former are fundamentally same as those of the latter." Akimoto (1955) reported that hemoilmenite is contained not only in dacite pumice but also in dacite pitchstone, dacite obsidian, andesite, and iron sand. The TRM characteristics of these rocks (and sand) containing hemoilmenite have been reviewed in Uyeda's $\mathrm{Ph}$. D thesis (Uyeda, 1958). These pioneering papers were truly insightful. The character of TRM of the Asio sample (schematic diagram of "Asio Type" in Nagata et al. (1955)) is equivalent to what we call in this paper type-B1 (or ntype) TRM. This type has not been recognized again until in 1999 two cases were reported (Sawada et al., 1999; Oshima and Ozima, 1999). Those authors also first recognized that the SRTRM-character of hemoilmenite is not limited to dacite pumice but occurs in other rocks, i.e., besides dacite pumice, dacite pitchstone posses SRTRM-character due to hemoilmenite.

In 1977, hemoilmenite exhibiting type-A SRTRM was found to exist in some granulite samples from Kilbourne Hole, New Mexico, USA (Padovani, 1977). In this case, the hemoilmenite crystals are surrounded by brown glass, indicating that these granulite samples have undergone later alteration of primary opaques and quenching. Recently, Sawada et al. (1999) have reported type-B1 hemoilmenite in dacite "lava" samples with glass in the groundmass from Sambe Volcano (SW of Japan). These reports imply that whatever the sample-pumice, pitchstone, obsidian, altered granulite or "lava" - , SRTRM hemoilmenite is expected, as long as it is a rapidly-quenched dacitic material that has not undergone subsequent decomposition.

Our standard process of the initial heating to acquire TRM is, heating at $600^{\circ} \mathrm{C}$ in air for 20 minutes and quenching to room temperature. As hemoilmenite is less susceptible to heating than titanomagnetite, and also as shown in the case of Pinatubo pumice samples (Ozima et al., 1992), there observed no appreciable difference in the behavior between thermal-demagnetization of NRM and that of TRM (acquired with our standard procedure). Therefore, we consider that our initial heating process to acquire TRM did not change magnetic behavior of our samples. Furthermore, as has shown in Ozima and Funaki (2001), in the case of our samples, the behavior (AF-demagnetization) of NRM well correlates with the behavior (AF-demagnetization and thermal-demagnetization) of TRM. That is, all samples of which NRM is stable/unstable against AF-field show type-A TRM (SRTRM)/type-B TRM. This distinct correlation between NRM and TRM supports our understanding that heating up to $600^{\circ} \mathrm{C}$ in the laboratory did not modify the remanence behavior of each sample. That is, the magnetic behavior (self-reversal) of TRM acquired in the laboratory of our samples (Figs. 3, 4, and 6) is regarded as almost the same as that of NRM.

As shown in Fig. 3 and 4, all pumice samples from Haruna Volcano do not exhibit identical apparent SRTRM. Comparing Fig. 3 with Fig. 4, we notice that (1) there are no big differences in magnetic behaviors between pumice flows and pumice falls, (2) the apparent magnetic behavior differs with the primary chemical composition $\left(\mathrm{TiO}_{2}\right.$-content or $x$-value) in hemoilmenite crystals. Samples in which hemoilmenite is poorer in $\mathrm{TiO}_{2}$-content $(\sim 30 \mathrm{wt} \%)$ (or $x \sim 0.582$ ) (all Futatsu-dake stage samples and Dai-ichi sample of calderastage) show type-A and type-B TRM. Samples in which hemoilmenite is richer in $\mathrm{TiO}_{2}$-content $(\sim 32 \mathrm{wt} \%$ ) (or $x$ $\sim 0.620$ )(caldera-stage samples except Dai-ichi) show only type-B TRM.

It is expected that pumice fall samples could be oxidized on the subsequent cooling more easily than pumice flow samples, and this subsolidus oxidation of hemoilmenite phenocrysts could affect the magnetic behaviors of those pumice samples more or less. Actually, we often notice some pumice block samples are brownish. This color in dacite pumice is an indication of subsolidus oxidation from which each pumice block has suffered. However, such subsolidus oxidation seems not to have been so effective for opaque minerals in this case. Evidently, we did not find any general difference in magnetic behaviors between pumice fall and pumice flow samples, i.e., both samples showed type-A and type-B TRM. The practical effect of such a slight and various degree of subsolidus oxidation in hemoilmenite phenocrysts to the magnetic behaviors could be replaced with the annealing effect during the subsequent cooling which is related to the order-disorder transition of hemoilmenite, as will be discussed below.

As mentioned above, the type of TRM behavior during thermal-demagnetization (type-A or type-B1 (n-type)), depends on the relative intensity of the normal component of TRM carried by the $\beta$-phase to that of the self-reversed component of TRM in the $\alpha$-phase. The absolute intensity of the SRTRM carried by the $\alpha$-phase in a sample depends on: the amount of hemoilmenite crystals, the chemical composition ( $\mathrm{TiO}_{2}$-content or $x$-value) of the hemoilmenite, and the mag- 
netic state of the hemoilmenite (whether the hemoilmenite is in the ordered state (ferrimagnetic with the crystal symmetry $\mathrm{R} \overline{3}$ ) or in the disordered state (anti-ferromagnetic + parasitic weak ferromagnetic with the crystal symmetry $\mathrm{R} \overline{3} \mathrm{C})$ ) which varies with the annealing of the sample. The number of hemoilmenite crystals could vary from magma to magma. However, for simplification, we neglect here this factor for all our samples. The chemical composition of hemoilmenite crystals from liquidus crystallization plays principal role in determining the characteristic remanent properties. For example, the intensity of saturation magnetization of the ordered phase, the order-disorder transition temperature, and the Curie point all are related to the chemical composition of hemoilmenite (Ishikawa, 1958; 1962). The magnetic state of hemoilmenite is critically dependent on annealing (Uyeda, 1957; Ishikawa, 1958; Ishikawa and Syono, 1962, 1963), which varies with cooling speed in air or in pyroclastic flow, which may be related to the size of the pumice block. Because of local variation in a volcanic deposit, the magnetic state of hemoilmenite could vary from one sample to another, such as in the group of Futatsu-dake stage plus Dai-ichi samples.

The experimental results of Uyeda (1957) demonstrate that appreciable intensity of SRTRM is acquired by a quenched $\alpha$-phase only within a small range of Fe/Ti chemical composition (Fig. 5(a)). In this case, the intensity of SRTRM directly correlates with the unique value of $x$. If the sample is annealed under certain conditions, however, the samples containing $\mathrm{TiO}_{2}$ less than $\sim 31 \mathrm{wt} \%(x \sim 0.60)$, which showed normal TRM in a quenched state, acquired SRTRM (Fig. 5(a)). Further detailed experiments show that the intensity of SRTRM of quenched hemoilmenite increases from a weak to a maximal value and finally again to almost null (or normal) in proportion to the annealing time (Ishikawa (1958), and Ishikawa and Syono (1962, 1963), Fig. 5(b)). Therefore, if we take into account the effect of annealing, it is easily understood that hemoilmenites containing $\mathrm{TiO}_{2}$ less than $\sim 31 \mathrm{wt} \%(x \sim 0.60)$ may display variable intensity of SRTRM according to their thermal history.

Our experimental results (Figs. 3 and 4) can be interpreted in light of these magnetic data. In our study, all samples in which the chemical composition of hemoilmenite crystals is $\mathrm{TiO}_{2} \sim 32 \mathrm{wt} \%(x \sim 0.62)$, acquired comparatively weak SRTRM, showing only type-B TRM. In these cases, apparently, hemoilmenite of this composition originally acquires only weak SRTRM and are not greatly susceptible to annealing. On the other hand, for the samples in which the chemical composition of hemoilmenite is $\mathrm{TiO}_{2} \sim 30 \mathrm{wt} \%(x \sim$ 0.582 ), they acquired variable SRTRM, from intense (typeA TRM) to weak (type-B or n-type TRM). Hemoilmenite of this composition in pumice can acquire intense SRTRM originally, which however, is lessened (or sometimes enhanced and then lessened) in proportion to the amount of annealing. For samples having a range of cooling rates (variation in annealing), the SRTRM will exhibit range in intensity.

In order to examine this hypothesis, we selected thermaldemagnetization curves of TRM of Futatsu-dake pumice fall samples $\left(\mathrm{TiO}_{2} \sim 30 \mathrm{wt} \%\right.$ or $\left.x \sim 0.582\right)$ from different levels in the deposit (upper, middle, and lower) (Fig. 6). It is
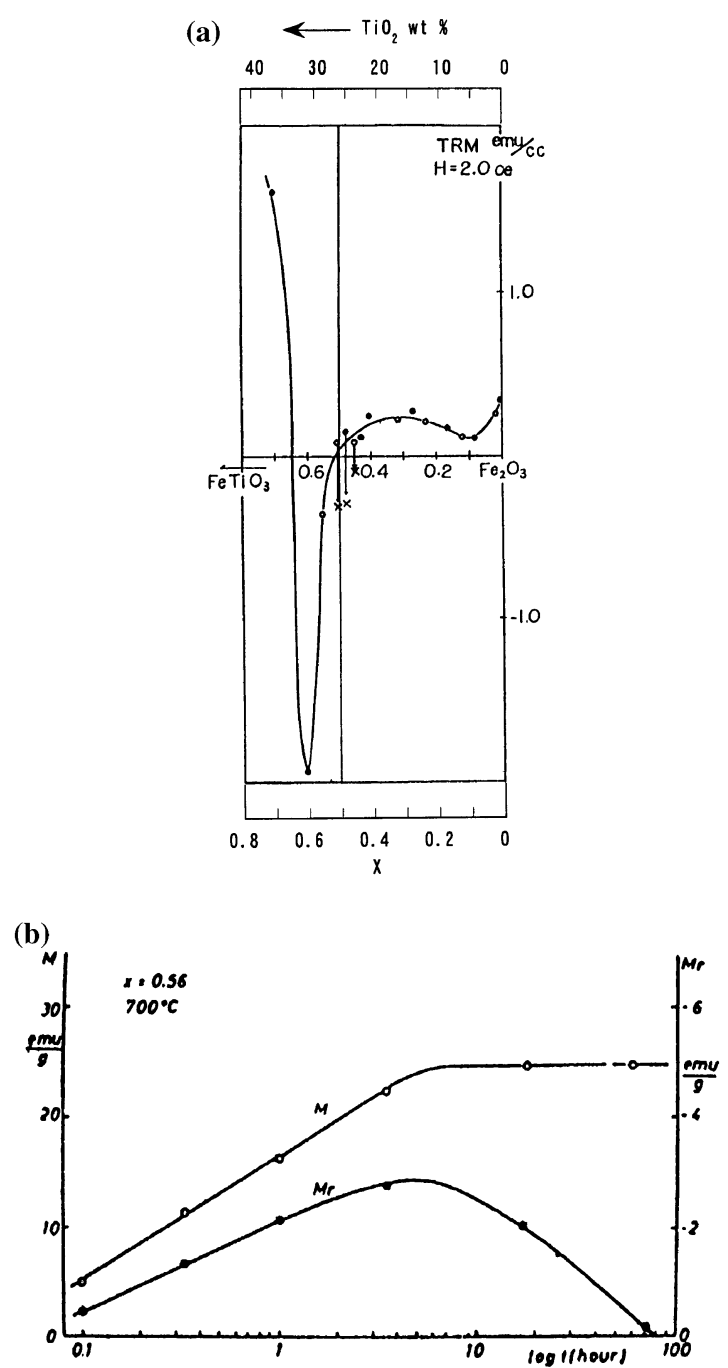

Fig. 5. (a) The intensity of TRM at room temperature vs. composition: TRMs represent total TRM produced by cooling in a field of $\mathrm{H}=2.0$ Oe $(200 \mu \mathrm{T}) . \bullet, \circ$ : specimens quenched from $1200^{\circ} \mathrm{C} . \times$ : annealed specimens (after Uyeda, 1957). The corresponding scales of the chemical composition in $\mathrm{TiO}_{2} \mathrm{wt} \%$ and $x$ (molecular fraction of ilmenite) are added by the authors. (b) $M$ : Magnetization at room temperature vs. annealing time at $700^{\circ} \mathrm{C}$. $M r$ : maximum SRTRM vs. annealing time at $700^{\circ}$ C. Sample: $\mathrm{Hm} 44 \mathrm{Il} 56\left(x=0.56\right.$, or $\left.\mathrm{TiO}_{2}=28.8 \mathrm{wt} \%\right)$ (after Ishikawa and Syono, 1962).

assumed that samples in the upper part cooled more quickly than those in the lower part. That is, there was less time for annealing in the upper layer as compared to the lower. Our results show that the higher the level, the more intense the SRTRM (type-A) (Fig. 6) and support the idea that the difference in the cooling speed controls the intensity of SRTRM in these samples.

\section{Conclusion}

The chemical composition in $\alpha$-phase phenocrysts in Haruna pumice samples correlates well with the remanent magnetic behavior of the samples. That is, samples in which the chemical composition in hemoilmenite crystals is $\mathrm{TiO}_{2}$ $\sim 30 \mathrm{wt} \%(x \sim 0.582)$ show a variety of remanent magnetic behavior (type-A $\sim$-B TRM), whereas those samples in which hemoilmenite crystals contain $\sim 32 \mathrm{wt} \% \mathrm{TiO}_{2}(x \sim$ $0.620)$ show only type-B TRM. The difference in the chem- 


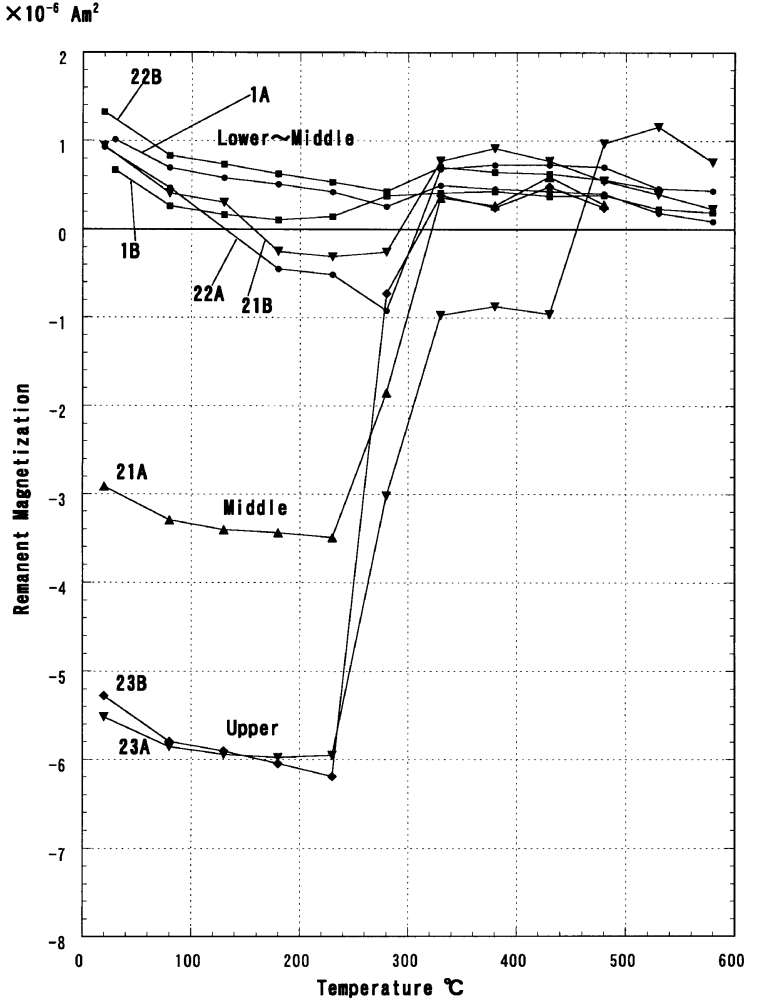

Fig. 6. Thermal-demagnetization of TRM of the Futatsu-dake pumice fall samples. The ordinate shows TRM of $2.4 \mathrm{~cm}$-core along the applied field. Numbers indicate samples shown in Table 1.

ical composition between these two groups of samples is a function of magma chemistry. Using the data of Uyeda (1957), Ishikawa (1958), and Ishikawa and Syono (1962, 1963), we conclude that the intensity of SRTRM depends on the amount of annealing within a certain range of $x$ (or $\mathrm{TiO}_{2-}$ content). That is, those $\mathrm{TiO}_{2}$-poorer (less than $\left.\sim 30 \mathrm{wt} \%\right)(x$ : less than $\sim 0.582$ ) samples, the variety of magnetic behavior was caused by difference in the speed of cooling. The result from Futatsu-dake pumice-fall samples that the remanence magnetic behavior corresponds to the level of the layer where the sample was deposited and cooled supports our implication.

Inasmuch as we could not derive an alternative model of SRTRM in this study, we still support the mechanism given by Ishikawa and Syono (1962, 1963). We believe, however, that further study on the magnetic properties of the hemoilmenite crystals contained in these Haruna samples and their geological evidences will ultimately contribute to a better understanding of the mechanism.

Acknowledgments. We are grateful to Dr. E. E. Larson of the University of Colorado, U. S. A. for his valuable comments and kind help in the language. We thank the two referees, one is $\mathrm{M}$. Prévot and the other is anonymous, for their valuable comments.

\section{References}

Akimoto, S., Magnetic properties of ferromagnetic minerals contained in igneous rocks, Japan, J. Geophys., 1(2), 1-31, 1955.

Heller, F., J. C. Carracedo, and V. Soler, Reversed magnetization in pyroclastics from the 1985 eruption of Nevado del Ruiz, Colombia, Nature, 324, 241-242, 1986.
Hoffman, K. A., Self-reversal of thermoremanent magnetization in the ilmenite-hematite system: order-disorder, symmetry and spin alignment, J. Geophys. Res., 97(B7), 10883-10895, 1992.

Hoffmann, V. and K. Th. Fehr, Micromagnetic, rockmagnetic and mineralogical studies on dacitic pumice from the Pinatubo eruption (1991, Philippines) showing self-reversed TRM, Geophys. Res. Lett., 23, 2835 2838, 1996.

Ishikawa, Y., An order-disorder transformation phenomenon in the $\mathrm{FeTiO}_{3}$ $\mathrm{Fe}_{2} \mathrm{O}_{3}$ solid solution series, J. Phys. Soc. Japan, 13, 828-837, 1958.

Ishikawa, Y., Magnetic properties of ilmenite-hematite system at low temperature, J. Phys. Soc. Japan, 17, 1835-1844, 1962.

Ishikawa, Y. and Y. Syono, Reverse thermo-remanent magnetism in the $\mathrm{FeTiO}_{3}-\mathrm{Fe}_{2} \mathrm{O}_{3}$ system, J. Phys. Soc. Japan, 17, B-I, 714-718, 1962.

Ishikawa, Y. and Y. Syono, Order-disorder transformation and reverse thermo-remanent magnetism in the $\mathrm{FeTiO}_{3}-\mathrm{Fe}_{2} \mathrm{O}_{3}$ system, J. Phys. Chem. Solids, 24, 517-528, 1963.

Kennedy, L. P., Self-reversed thermoremanent magnetization in a late Brunhes dacite pumice, J. Geomag. Geoelectr., 33, 429-448, 1981.

Lawson, C. A., G. L. Nord, Jr., and D. E. Champion, Fe-Ti oxide mineralogy and the origin of normal and reverse remanent magnetization in dacitic pumice blocks from Mt. Shasta, California, Phys. Earth Planet. Inter., 46, 270-288, 1987.

Nagata, T., S. Akimoto, and S. Uyeda, Reverse thermo-remanent magnetism, Proc. Japan. Acad., 27, 643-645, 1951.

Nagata, T., S. Akimoto, and S. Uyeda, Self-reversal of thermo-remanent magnetism of igneous rocks (3), J. Geomag. Geoelectr., 5, 168-184, 1953.

Nagata, T., S. Akimoto, S. Uyeda, K. Momose, and E. Asami, Reverse magnetization of rocks and its connection with the geomagnetic field, J. Geomag. Geoelectr., 6, 182-193, 1955.

Oshima, O., Compositional variation of magnetite during the eruption and its bearing on the stage of crystallization of magma of Futatsu-dake, Haruna Volcano, Mineral. J., 6, 249-263, 1971.

Oshima, O., Compositional variation of Fe-Ti oxides in the rocks of Haruna Volcano, Bull. Volc. Soc. Japan, Ser. 2, 17, 111-112, 1972a (in Japanese). Oshima, O., Pyroclastic flows and related deposits of Haruna Volcano, Bull. Volc. Soc. Japan, Ser. 2, 17, 156-157, 1972b (in Japanese).

Oshima, O., Mineralogical aspects of volcanic eruption, Bull. Volc. Soc Japan, Ser. 2, 20, Special Issue, 275-298, 1975 (in Japanese).

Oshima, O., Fe-Ti oxide minerals in pumices (1), Bull. Volc. Soc. Japan, Ser. 2, 23, 297, 1978 (in Japanese).

Oshima, O., Reduction decomposition of hemoilmenite in a cooling magma and its relation to the changes of magnetization of rocks, Rock Magnetism and Paleogeophysics, 9, 102-105, 1982.

Oshima, O. and M. Ozima, Geomagnetic study of pyroclastic rocks of Haruna Volcano with special reference to the self-reversal thermoremanent magnetization, Abstract of the Volc. Soc. of Japan, 104, 1999 (in Japanese).

Ozima, M. and M. Funaki, Magnetic properties of hemoilmenite single crystals in Haruna dacite pumice revealed by the Bitter technique, with special reference to self-reversal of thermoremanent magnetization, Earth Planets Space, 53, 111-119, 2001

Ozima, M., M. Funaki, N. Hamada, S. Aramaki, and T. Fujii, Self-reversal of thermo-remanent magnetization in pyroclastics from the 1991 eruption of Mt. Pinatubo, Philippines, J. Geomag. Geoelectr., 44, 979-984, 1992.

Padovani, E. R., Granulite facies xenoliths from Kilbourne Hole maar, New Mexico and their bearing on deep crustal evolution, Thesis, Univ. of Tex. at Dallas, Richardson, 1977.

Prévot, M., K. A. Hoffman, A. Goguitchaichvili, J.-C. Doukhan, V. Shcherbakov, and M. Bina, The mechanism of self-reversal of thermoremanence in natural hemoilmenite crystals: new experimental data and model, Phys. Earth Planet. Inter, 126, 75-92, 2001.

Sawada, Y., M. Hyodo, M. Fukue, Y. Asahara, C. Kashine, and M. Tateno, Magnetic mineral showing self-reversed TRM from Quaternary Sambe and Daisen Volcanoes, SW Japan Arc, Abstract of the Volc. Soc. of Japan 1, 1999 (in Japanese).

Uyeda, S., Thermo-remanent magnetism and coercive force of the ilmenitehematite series, J. Geomag. Geoelectr., 9, 61-78, 1957.

Uyeda, S., Thermo-remanent magnetism as a medium of paleomagnetism, with special reference to reverse thermo-remanent magnetism, Jap. J. Geophys., 2, 1-123, 1958.

M. Ozima (e-mail: ozima@nipr.ac.jp) 